\title{
Forensic Methods of Identifying Corpses with Unknown Identity
}

\author{
Ovidiu Andrei Hamburda
}

Faculty of "Economic Sciences and Public Administration," Law Specialization, University "Ștefan cel Mare," Romania Master in Criminal Sciences at "Dimitrie Cantemir" Christian University of Bucharest, ovidiu.andrei20@yahoo.com

\begin{abstract}
Finding the truth is the most difficult process, especially in a society that reveals itself as a highspeed field, whose passengers combine good and evil, honor and dishonesty, respect for the law and crime. Identification of dead bodies is one of the most common but complicated activities that the magistrate, criminal investigation dead bodies, criminalist or forensic doctor encounters, because compared to the living people who appreciate both the static signs, the dynamic signs and the functional features noted by different gestures, attitudes, etc. only the static forms and the personal objects on them or the clothing are appreciated in the case of dead bodies. Most procedures claim certain data and information to be compared, such as DNA, fingerprints, dentition, etc., but if they do not exist, comparison with the rest of the population is impossible. To identify a person, the forensic research bodies also found other methods, such as the over-projection method, the reconstruction of the skull physiognomy, the skeletal identification, dental or dental identification.
\end{abstract}

KEYWORDS: clothes, dead bodies, dentition, DNA, research, skeleton, unknown

\section{Introduction}

In the society where we living, personal and national security is very easy to attack, hence the need for more stringent and trustworthy measures to identify and secure our identity. Although in the book of Alexander Dumas - Martin Guerre, identity was established by cunning and confession, in today's world, a simple comparison of DNA would solve the problem, beyond any reasonable uncertainty (Thompson and Black 2007). The process of identifying living or deceased persons, objects or even phenomenons related to the illicit deed through forensic methods, with the aim of establishing truthfulness in the judicial process, is the whole of the idea of forensic identification. Victims of accidents or catastrophes, interference by the perpetrator on the dead body, victims of arson, etc. pose other problems in identifying.

It is necessary to have a close and effective collaboration between criminologists and legal medicine specialists for the good process of identification. You must follow certain steps, from which criminals should not deviate for the identification of a corpse of unknown identity (Belis 1995). It should be noted that these are also required in addition to the type sheet with the following elements:

Capture pointing of the body, metric shooting of the corpse in the way it was found, as well as the objects found on it, digital replication, sub-nail collection, hair picking (Thompson and Black 2007). Samples of great significance are biological ones that are high, packaged and sealed for expertise or for preservation.

The exact description of the external signs, particular signs, dentition, garments, and any other objects on the body, all this information is written in the file, then necropsy is made, the blood group, possibly alcoholism, is established.

Clothes, footwear, objects found on the body are subject to forensic expertise.

\section{Overshooting method}

In previous decades, forensic anthropology and forensic odontology have played a special role in identifying human remains (Stancu 2017). Technically speaking, this method consists of designing or overlaying the image of the skull to be identified over a photographic image of a missing person, supposedly belonging to the skull. This method was first used in 1960 in Calcutta, India (Cârjan 2001). The special apparatus required for the application of this method is currently held by the National Criminal Investigation Institute. To perform the comparative examination, the skull should be taken in a position similar to that of the reference picture head, which is performed by means of a special device. 
The two images overlap on a screen to determine the similarities or differences of the anatomical and anthropometric elements, evaluated as landmarks, the result being fixed by shooting. Thus, the main means of illustrating the anthropologist's findings is represented by a photogram. Electronic image overlay is an improved version of over-projection, based on the electronic combination of unknown skull images and those of the missing person.

\section{Reconstitution of the physiognomy after the skull}

A constituent part of the judicial effort as well as a routine necessity is the identification of the identities and the reconstruction of the bodies discovered on the spot, whether it is murder or not. (Cantemir 1969).

Mutilated, dismembered bodies, body fragments, etc. can be found. If the examination of identity papers is not possible, one of the forensic investigator's remarkable weapons is the reconstruction of the physiognomy after the skull.

Reconstitution of the human figure after the skull has to include the case study at an early stage in order to determine sex, age and craniometric, typological or pathological characters, accurately measure all the bones, specify the correlations between them, reconstruct and restore absent bones.

The process of graphical fixation of the skull and the process of graphic reconstruction form the graphic reconstruction, which is designed to follow the design of the soft tissue contours by means of thickness standards, then to reconstruct the graphic or the plastic one.

Drawings will be made on the front skirt, the profile and the top. The particularities of missing persons such as hair, mustache or various objects will be emphasized.

After all these operations have been performed, the skull physiognomy can be reconstituted. If this method is applied correctly, the results of this kind of identification are remarkable, the similarity reaching the degree of perfection in most cases.

\section{Identification of skeletal parts}

Identification of skeletal parts or anthropological identification on bone material has as central objective the identification of an unknown deceased person. The osteological forensic expertise carried out by the anthropologist is able to determine whether the osteological traces are of human nature if we are in the presence of a whole skeleton or if the bones belong to more than one person. (Stefănescu 1990). At the same time, data on age, sex, waist and possible illnesses that the person might have suffered during his or her lifetime can be determined. As early as the 19th century, there have been attempts to identify corpses after bone debris, when some data on the duration of bone stay in the earth appeared in the literature.

When certain skeletal debris is found, the specialist, from the first stage of the process, must determine whether the remnants are of human nature. An important role in determining the stature and weight of the deceased person has the bones of the foot or arm.

Long-term bone degradation signs that are under development are expressed by color change, and transverse and longitudinal clefts appear on the surface of the bone.

A good indicator of age is the sternum because it is not a weight support bone and is not affected by birth, which determines the interest in examining how the ribs are attached to the sternum. Pelvic bones help identify sex, men are narrower and deeper, whereas in women the pelvis is wider and deeper (Pășescu 2000).

\section{Identification of the dental system and dental work}

The identification of dental carcasses and dental work, also known as forensic odontology, can be defined as the science of dental expertise in the judiciary, an expertise that has a very important place in the identification of persons and cadavers.

Forensic experts frequently use dental and dental work to identify themselves because they retain their properties for a long time and play a decisive role in identifying unknown corpses, decomposed, sheep-blooming, corroded, carbonized or fragmented bodies.

The anatomical and morphological features of the dental system help determine the sex, and the age of the corpse is based on teeth wear criteria. The membership of a species very easily determined, 
the human dentition being different from that of the animals. Maxillary incisors are proportionally higher in humans than in mammals, smaller canines than animals, and premolars and molars have rounded cusps separated by distinct ditches. Breed membership is established taking into account certain morphological aspects present in different species (Stimson and Mertz 2000, 53).

Estimation of sex, as the teeth do not show sexual dimorphism, is very difficult to establish. As a peculiarity that might be the difference between women and men is that crown dimensions tend to be higher in males than in females, or it can also be determined by the Y chromosome test. Estimation of age can be made by comparing the stage of development of dentition to a person whose age is unknown, with tables of dental development characteristics for each age.

\section{Identification through portrait photography expertise}

Throughout his life, man accumulates a sequence of physiological changes due to his biological, traumatic, medical or surgical interventions such as surgery or maladies - but man nevertheless presents an objective and undeniable individuality. The scientific basis of the portrait photography expertise lies precisely in this invariability and certainty of individuality (Robe 2013).

In applying this method, two categories of signals are used, respectively anatomical or static and functional or dynamic. An important role is played by particular signs, clothing and portable objects whose characteristics make identification easy. (Buzatu 2013 92).

The method consists in confronting a more recent photograph representing the missing person's figure, with the photograph of the body to be identified. Their comparative examination will result in the determination of whether two or more photos represent the image of one person or two different people.

The method consists in confronting a more recent photograph representing the missing person's figure, with the photograph of the body to be identified. Their comparative examination will result in the determination of whether two or more photos represent the image of one person or two different people.

1. Comparing by confronting traits. The most simplified procedure is to perform the comparative examination by placing the pictures side by side, that of the unknown person to the left and the known one to the right. The next step will be to find the common elements of the two photos. Both the differences and the similarities will be retained and described in the final report in the expert report; these items will be marked on both photos. In the case of the dismantled bodies, the body fragments will be photographed separately as well as in their reconstituted form (Leung 2008, 17).

2. Measuring angular values. Represented by a procedure by which tangential lines are drawn to certain fixed elements of the human figure, pre-established before, to the extremities of other elements. Using mathematical calculations and formulas, you will find that the two photos contain the same person's image.

3. Designing common points. Another method involves a procedure whereby the two photographs under comparison and analysis are made on different scales. It is paramount that the images are made from the front plan. The large image will be placed on a sheet of paper at the bottom of the paper, and the smaller one above the first. Similar items in the two photos merge and find out if the two images reflect the same person.

4. The method of grid or square mesh. A line of parallel lines will be applied at equal distances, both vertically and horizontally. These will be marked with figures and letters, which consist of geometric figures in which the elements of the figure or the part of the figure are arranged. The line spacing must be as small as possible to make the analysis as accurate as possible (Fischman 2005).

\section{Conclusions}

Truth is the supreme value of knowledge, which gives it a leading role in gnoseology, and its finding depends directly on the identity that is attributed to each person. The purpose of forensic research is to support investigative and judicial processes to detect traces in raw materials, from which there is the possibility of building events and activities. The basis of the forensic activity lies in the principle of the Locard: "Any contacts leave traces". The science of forensics is based on the truth "told" by evidence here, 
resulting in a close connection with criminal science. Karl Popper, the philosopher, drew attention to the fact that scientific evidence is becoming more and more important in criminal justice, an evolution that has been determined by the increasing need for their use. The detection of offenders, the identification of recidivists, the detection of criminal offenses and guilt, the determination of the circumstances in which they were produced, and other situations, including those relating to the settlement of civil litigation, necessarily require the identification of both the living person, the deceased and the objects.

\section{References}

Beliș, Vladimir. 1995. Forensic Medicine. Bucharest: Teora Publishing House.

Buzatu, Nicoleta-Elena. 2013. Forensic. Bucharest: Pro Universitaria Publishing House.

Cantemir, Riscutia. 1969. "Reconstitution of the physiognomy after skull." In Problems of legal medicine and forensics. No 7-8.

Cârjan, Lazăr. 2001. Criminalistic Treaty. Bucharest: Curtea Veche Publishing House.

Claridge, Jack. 2015. "Identifying the Victim.” In Explore Forensics, http://www.exploreforensics.co.uk/identifying-thevictim.html accessed on 20.07.2019.

Fischman, S.L. 2005. The use of medical and dental radiographs in identification, Int. Dent J.

Leung, Carl KK. 2008. "Forensic Odontology." In Dental Bulletin. No 11. Nov.: 16-20.

Pășescu, Gheorghe. 2000. Forensic Interpretation at the Place of Deception. Bucharest: National Publishing House.

Robe, Mihail Lucian. 2013. "Expert of Portrait Photography”. In Criminalistics Magazine, No. 4.

Ştefănescu, Paul and Cârjan, Lazăr. 1990. Science vs. Crime: Criminology, Criminology. Bucharest: Legal Medicine, Scientific Publising House.

Stimson, Paul and Mertz, Curtis. 2000. Forensic Denstristry, CRC Press LLC.

Thompson, Tim and Black, Sue. 2007. Forensic Human Identification. An Introduction, CRC Press Publishing, Taylor \& Francis Group, Boca Raton. 